\title{
Glyphosate Sobre a Resistência À FerRugem (Puccinia psidii) do EUCALIPTO ${ }^{1}$
}

\author{
Glyphosate on Eucalyptus Resistance to Rust (Puccinia psidii)
}

\author{
TUFFI SANTOS, L.D. ${ }^{2}$, NEVES GRAÇA, R. ${ }^{3}$, ALFENAS, A.C. ${ }^{4}$, FERREIRA, F.A. ${ }^{5}$, \\ FERREIRA, L.R. ${ }^{6}$ e ODA, S. ${ }^{7}$
}

\begin{abstract}
RESUMO - O glyphosate é o herbicida mais usado no controle de plantas daninhas em eucalipto, atuando diretamente na rota do ácido chiquímico, principal via de formação de compostos ligados aos mecanismos de defesa das plantas, como: lignina, ácido salicítico e fitoalexinas. Assim, o contato do glyphosate com as folhas do eucalipto pode levar a conseqüências importantes sobre a resistência a doenças. Objetivou-se neste estudo avaliar o envolvimento do glyphosate, via deriva, na severidade da ferrugem causada por Puccinia psidii em genótipos de eucalipto com diferentes niveis de resistência ao patógeno. Para isso, mudas de quatro clones - dois heterozigotos resistentes à ferrugem (UFVO1 e UFVO2) e dois homozigotos suscetiveis (UFVO3 e UFVO4) - foram submetidas às subdoses de 0 (testemunha); 28,8; 57,6; 86,4; e 115,2 $\mathrm{g} \mathrm{ha}^{-1}$ de glyphosate, simulando deriva. Três dias após a aplicação do glyphosate, as plantas foram inoculadas com o isolado monopustular UFV1 de P. psidii, obtido de Eucalyptus grandis, na região de Itapetininga, SP. Aos 21 dias após a inoculação, foram avaliados a severidade de ferrugem, utilizando-se uma escala diagramática com quatro classes (SO e S1 resistentes à ferrugem e S2 e S3 suscetiveis), o número de pústulas $\mathrm{cm}^{-2}$ de área foliar, a área foliar lesionada pela ferrugem, o número médio de urediniósporos $\mathrm{cm}^{-2}$ de área foliar, o número médio de urediniósporos/pústula e a porcentagem de intoxicação pelo glyphosate. O clone UFVO4 foi o mais sensivel ao glyphosate, enquanto o UFVO1 apresentou maior tolerância ao herbicida. O glyphosate não alterou o nivel de resistência à ferrugem nos genótipos resistentes (UFV01 e UFVO2) que apresentaram ausência de pústulas nas folhas, tanto em plantas expostas à deriva quanto nas testemunhas. Para os demais clones, manteve-se a suscetibilidade à ferrugem, embora, com o aumento das doses de glyphosate, tenha se observado diminuição da severidade da doença. Conclui-se que o glyphosate não afetou a resistência do eucalipto a Puccinia psidii, ocorrendo diminuição da severidade da doença em plantas expostas ao glyphosate via deriva, e que existe tolerância diferencial entre os clones ao herbicida.
\end{abstract}

Palavras-chave: Puccinia psidii, herbicida, doença de plantas, Eucalyptus spp.

ABSTRACT - Glyphosate is the herbicide most applied on eucalyptus plantations for weed control, acting directly on the shikimic acid pathway, the main via for the formation of compounds connected with the natural defenses of the plant, such as lignin, salicytic acid and phytoalexins. Thus, glyphosate contact with the leaves of the plant through drift may have important consequences for disease resistance. The aim of our research was to evaluate glyphosate drift involvement with severity of rust caused by Puccinia psidii in genotypes with different levels of resistance to the pathogen, after inoculation in a controlled environment. Seedlings of four clones, two heterozygote clones resistant to rust (UFVO1 and UFV02) and two homozygote clones susceptible to rust (UFV03 and UFV04) were submitted to sub-doses of O (control); 28.8, 57.6, 86.4 and $115.2 \mathrm{~g} \mathrm{ha}^{-1}$ of glyphosate simulating drift. Three days after glyphosate application,

1 Recebido para publicação em 11.10.2006 e na forma revisada em 27.2.2007.

Parte da Tese de Doutorado do primeiro autor (bolsista do CNPq).

2 Pós-doutorando em Fitotecnia, Departamento de Fitotecnia, Universidade Federal de Viçosa - DFT/UFV, 36570-000 ViçosaMG, <ltuffi@yahoo.com.br>; ${ }^{3}$ Mestrando em Fitopatologia - DFP/UFV; ${ }^{4}$ Prof. do Departamento de Fitopatologia - DFP/UFV; ${ }^{5}$ Prof. Titular - DFT/UFV; ${ }^{6}$ Prof. Associado - DFT/UFV; ${ }^{7}$ Eng.-Agrônomo Suzano Papel e Celulose. 


\begin{abstract}
the plants were inoculated with UFVO1 isolated from P. psidii obtained from Eucalyptus grandis in the Itapetininga region. On day 21 after inoculation, the following parameters were evaluated: rust intensity, by means of a diagrammatic scale with four classes of severity (SO and $S 2$ resistant to rust and S2 and S3 susceptible to rust), number of pustules per leaf area, area affected by rust, average number of urediniospores $\mathrm{cm}^{2}$, glyphosate percentage intoxication, and average number of urediniospores/pustule. Clone UFVO4 was found to be the most susceptible while UFVO1 was the most tolerant to the herbicide. Drift did not change the level of resistance to rust with respect to the resistant genotypes (UFVO1 and UFVO2) which presented no pustule both in plants exposed to drift and control plants. Susceptibility was maintained for the other clones, with a higher pustule density and higher percentage of affected area becoming evident for clone UFV03. For some clones susceptible to rust, rust severity decreased with glyphosate dosage increase. It was concluded that glyphosate did not affect eucalyptus resistance to Puccinia psidii and that there is differential tolerance to the herbicide among the clones.
\end{abstract}

Keywords: Puccinia psidii, herbicide, plant disease, Eucalyptus spp.

\section{INTRODUÇÃO}

A ferrugem causada por Puccinia psidii é atualmente uma das principais doenças do eucalipto no Brasil, provocando prejuízos em viveiro e no campo. Seu controle baseia-se principalmente no uso de espécies, clones e progênies resistentes. $\mathrm{O}$ uso de alguns fungicidas, o plantio e o corte raso capaz de possibilitar o crescimento das plantas no campo em épocas desfavoráveis ao patógeno também são práticas eficientes de controle da doença (Alfenas et al., 2004).

A herança da resistência a $P$. psidii em Eucalyptus grandis é condicionada por um gene de efeito principal, denominado Ppr-1, cujo conhecimento possibilitou a identificação e seleção de genótipos homozigóticos e heterozigóticos para resistência, bem como de genótipos suscetiveis (Junghans et al., 2003).

Atualmente, tem-se levantado a hipótese de associação dos danos causados pela deriva do glyphosate com o aumento da incidência e severidade da ferrugem do eucalipto. A intoxicação do eucalipto por glyphosate caracterizase pela presença de folhas cloróticas, evoluindo em alguns casos para necroses, superbrotamento e redução do crescimento da planta. Outros distúrbios e alterações morfológicas do eucalipto, como senescên cia acentuada de folhas e morte dos ponteiros, têm sido atribuídos aos efeitos do glyphosate. A deriva pode acarretar prejuízos no desenvolvimento do eucalipto ou mesmo a diminuição do estande, devido à morte de plantas mais jovens (Tuffi Santos et al., 2005).
O glyphosate é um herbicida sistêmico, não-seletivo, aplicado em pós-emergência e de amplo espectro de ação, sendo o principal produto ativo utilizado no controle de plantas daninhas na eucaliptocultura. Seu mecanismo de ação interfere na rota do ácido chiquímico, precursor envolvido na defesa de plantas a patógenos, destacando-se: taninos, antocianinas, ácido salicílico, lignina, flavonas, isoflavonas e cumarinas (Buchanan et al., 2000; Srivastava, 2001).

Além dos efeitos diretos do glyphosate nas plantas, o herbicida pode estar favorecendo a infecção do eucalipto por patógenos, devido à queda das defesas da planta pelo comprometimento ou interrupção da sintese de lignina, fitoalexinas (Lévesque \& Rahe, 1992; Rizzardi et al., 2003) e de outros compostos.

Diante da importância desse herbicida na eucaliptocultura, objetivou-se avaliar a influência da deriva de glyphosate na severidade da ferrugem causada por Puccinia psidii em genótipos de eucalipto com diferentes níveis de resistência à doença.

\section{MATERIAL E MÉTODOS}

O presente estudo foi composto por dois ensaios, sendo o primeiro realizado no verão, entre janeiro e março de 2006, e repetido nos meses de maio e julho de 2006 (outono/ inverno), mantendo-se a mesma metodologia.

Mudas de quatro clones híbridos de E. grandis da Suzano Papel e Celulose, sendo dois heterozigotos resistentes à ferrugem do 
eucalipto ( $U F V O 1$ e $U F V 02$ ) e dois suscetiveis (UFVO3 e UFVO4), foram padronizadas quanto à altura e idade e, posteriormente, transplantadas e cultivadas em vasos com capacidade para $6 \mathrm{~L}$, contendo substrato constituído de $3 / 4$ de solo argiloso e 1/4 de areia, adubado com $120 \mathrm{~g}$ de N- $\mathrm{P}_{2} \mathrm{O}_{5}-\mathrm{K}_{2} \mathrm{O}$ (6-30-6) e 7,2 g de calcário na proporção de $\mathrm{Ca}: \mathrm{Mg}=4: 1$ equivalentes. Após o transplantio, realizaramse adubações quinzenais de cobertura com 1,5 g por vaso de uma mistura de minerais (1515-20 de N- $\mathrm{P}_{2} \mathrm{O}_{5}-\mathrm{K}_{2} \mathrm{O}+$ pequenas quantidades de $\mathrm{Ca}, \mathrm{S}, \mathrm{Mg}, \mathrm{B}, \mathrm{Zn}$, Mn e Fe), previamente dissolvida em $100 \mathrm{~mL}$ de água.

Utilizou-se delineamento experimental de blocos casualizados com cinco repetições, em esquema fatorial $5 \times 4$ (cinco subdoses e quatro clones), sendo considerado como parcela experimental cada vaso contendo uma planta. As plantas de eucalipto receberam as subdoses de 28,$8 ; 57,6 ; 86,4$; e $115,2 \mathrm{~g}^{-1}{ }^{-1}$ de glyphosate simulando uma deriva, aplicado como solução aquosa da formulação comercial Scout ${ }^{\circledR}$. Como comparação, aplicou-se água no grupo de plantas correspondentes à testemunha (subdose 0).

A aplicação foi feita diretamente sobre as plantas, que se encontravam com 30 dias após o transplantio e aproximadamente $0,4 \mathrm{~m}$ de altura, utilizando-se pulverizador costal com pressão constante, pressurizado a $\mathrm{CO}_{2}$, munido de barra com dois bicos com pontas tipo leque TT 11002 , operando a $250 \mathrm{kPa}$ de pressão e volume de calda correspondente a $200 \mathrm{~L} \mathrm{ha}^{-1}$.

Dois dias após a simulação da deriva do glyphosate, as plantas foram inoculadas com um isolado UFV-1 de P. psidii obtido de Eucalyptus sp., na região de Itapetininga-SP. $\mathrm{O}$ isolado foi previamente multiplicado em mudas de jambeiro (Sygyzium jambos), e os urediniós poros produzidos foram coletados aos 12 dias após a inoculação, suspensos em água com Tween $80^{\circledR}(0,05 \%)$ e atomizados $\left(2 \times 10^{4}\right.$ urediniósporos $\left.\mathrm{mL}^{-1}\right)$ homogeneamente em ambas as faces do limbo foliar, com o auxílio de atomizador De Vilbss $\mathrm{n}^{\circ} 15$, acoplado a um

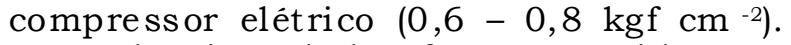
As mudas inoculadas foram mantidas em câmara de nevoeiro, no escuro, por 24 horas e posteriormente levadas para câmara de crescimento a $22{ }^{\circ} \mathrm{C}$, com fotoperíodo de 12 horas (Ruiz et al., 1989) e intensidade luminosa de $40 \mu$ moles de fótons $\mathrm{m}^{2} \mathrm{~s}^{-1}$. As avaliações foram realizadas aos 21 dias após a inoculação, utilizando-se uma escala diagramática com quatro classes de severidade (S0, S1, S2 e S3), de acordo com Junghans et al. (2003), sendo plantas com S0 e S1 resistentes à ferrugem e S2 e S3 suscetiveis. $\mathrm{Na}$ haste principal das mudas foram selecionadas, no segundo par de folhas apical, folhas totalmente expandidas representativas do estado de infecção da planta, sendo estas fotografadas e digitalizadas, para quantificação da porcentagem de área afetada pela ferrugem e da área média por pústula. Após a digitalização das folhas, retiraram-se quatro discos, de $1,2 \mathrm{~cm}$ de diâmetro, da região central de cada uma. Os quatro discos coletados por folha foram colocados em tubos de ensaio com $3 \mathrm{~mL}$ de água + Tween $80(0,1 \%)$ e agitados em vortex por um minuto, realizando-se duas leituras por tubo em câmara de Neubauer, para determinação do número médio de urediniósporos por área foliar. Com o número de pústulas por área foliar e de urediniósporos por área, pôde-se obter o número médio de urediniós poros produzidos por pústula. A quantificação da porcentagem de área afetada pela ferrugem e da área média por pústula foi obtida com auxílio do software Image-Pro Plus.

Além do efeito do herbicida sobre a intensidade da ferrugem, foram avaliadas diariamente possiveis modificações morfológicas na parte aérea das plantas e, aos 21 dias após a aplicação (DAA), realizou-se a avaliação visual da porcentagem de intoxicação causada pelo glyphosate, de acordo com escala proposta por Franz (1972). Tal escala baseia-se na porcentagem da área foliar das plantas com sintomas de intoxicação em relação à testemunha, variando de 0 a $100 \%$ de intoxicação, em que 0 corresponde à ausência de sintomas visiveis e $100 \%$ à morte das plantas.

Os dados foram submetidos à análise estatística pelo teste $\mathrm{F}$ a $5 \%$ de probabilidade, sendo ajustadas equações de regressão para intoxicação das plantas, área afetada com ferrugem, número de urediniósporos por pústulas e número de urediniósporos por área foliar.

\section{RESULTADOS E DISCUSSÃO}

Plantas tratadas com glyphosate, nas subdoses superiores a 57,6 $\mathrm{g} \mathrm{ha}^{-1}$, apresentaram sintomas de murcha e clorose nas 
regiões apicais da parte aérea, verificados a partir do sexto dia após aplicação (DAA). Necroses, localizadas principalmente nos bordos foliares, eram visiveis em plantas expostas a $115,2 \mathrm{~g} \mathrm{ha}^{-1}$ de glyphosate. Os sintomas foliares observados foram similares nos dois experimentos, porém com maior intensidade naquele realizado no outono/ inverno, em que foi verificada, nos quatro clones, a morte dos ápices e o surgimento de brotações anormais em grande parte das plantas tratadas com 115,2 $\mathrm{g} \mathrm{ha}^{-1}$ de glyphosate (Figura 1). As injúrias descritas estão de acordo com os resultados observados por Tuffi Santos et al. (2005) e Tuffi Santos et al. (2007) para clones de eucalipto submetidos à deriva simulada de glyphosate. Sintomas semelhantes foram encontrados em outras espécies herbáceas e arbóreas submetidas à deriva de glyphosate, como algodão (Miller et al., 2004; Yamashita \& Guimarães, 2005), varjão (Parkia multijulga) (Yamashita et al., 2006) e teca (Tectona grandis) (Vieira et al., 2006).

A intoxicação das plantas variou de acordo com as subdoses dos herbicidas testados $(\mathrm{p}<0,05)$ aos $21 \mathrm{DAA}$, sendo tanto maior quanto maiores as subdoses de glyphosate nos dois ensaios. O clone UFVO4 foi o mais suscetivel ao glyphosate, alcançando $20 \%$ de intoxicação no ensaio realizado no verão e $48 \%$ no outono/ inverno em plantas expostas a $115,2 \mathrm{~g} \mathrm{ha}^{-1} \mathrm{de}$ glyphosate (Figura 2). Por sua vez, o clone
UFVO1 apresentou maior tolerância ao herbicida, chegando a apenas $6,8 \%$ de intoxicação no ensaio 1 , quando para aplicação da maior dose do produto (Figura 2). Os resultados confirmam a diferença de tolerância ao glyphosate entre os clones. O comportamento diferencial entre os genótipos submetidos à deriva de glyphosate foi relatado por Tuffi Santos et al. (2007), em que o clone de E. grandis foi mais suscetivel ao herbicida que clones de E. urophylla e híbrido urograndis. Em trabalho semelhante, Tuffi Santos et al. (2006b) constataram maior tolerância ao glyphosate em $E$. resinifera, quando comparado a E. grandis, E. urophylla, E. saligna e E. pellita.

A porcentagem de intoxicação das plantas observada no ensaio realizado no outono/ inverno é praticamente o dobro daquela do realizado no verão (Figura 2), ressaltando a maior sensibilidade do eucalipto ao glyphosate nas épocas frias do ano, o que pode ser atribuído ao menor metabolismo das plantas expostas a condições subótimas.

Não se observaram pústulas nos clones resistentes à ferrugem, UFVO1 e UFVO2, independentemente do tratamento com glyphosate e da época de realização do ensaio (Tabela 1), sendo atribuida nota SO de severidade. Esses resultados indicam que a deriva de glyphosate não modificou a resistência à ferrugem dos clones resistentes testados (UFV01 e UFV02).
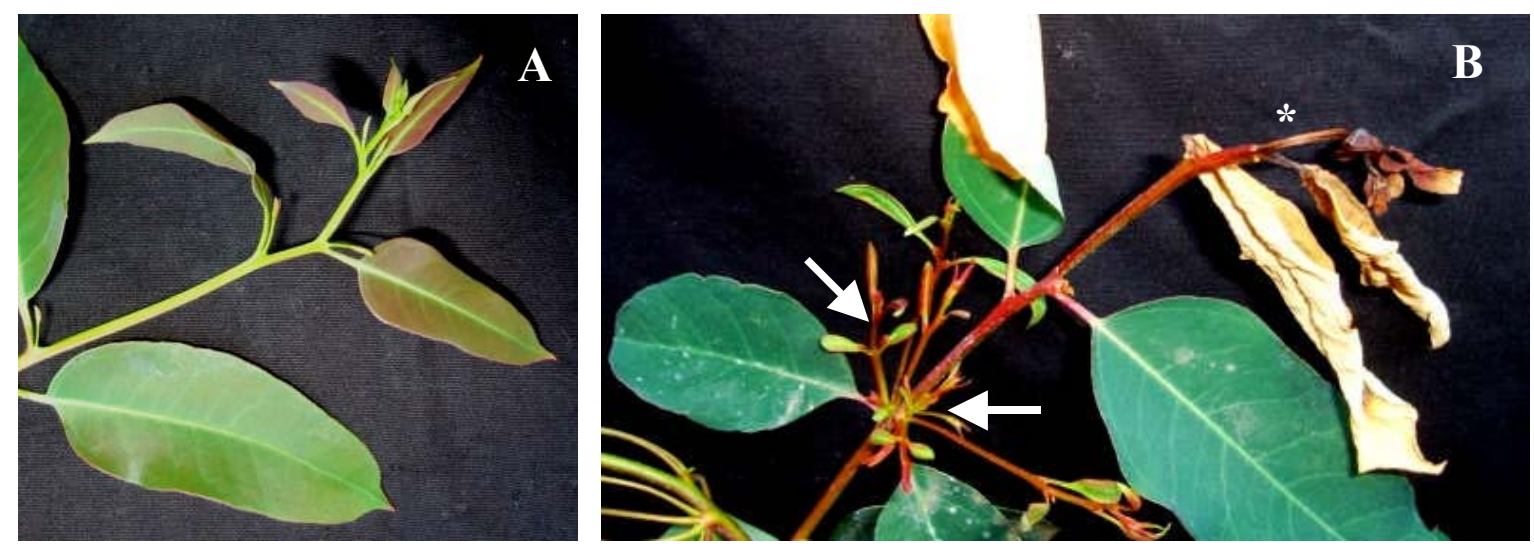

Setas indicam superbrotação anormal e * morte do ápice caulinar.

Figura 1 - Aspecto do ápice caulinar de eucalipto de plantas testemunhas (A) e plantas tratadas com 115,2 $\mathrm{g}^{-1} \mathrm{de}^{-\mathrm{glyphosate}}$ (B), 21 dias após aplicação. 

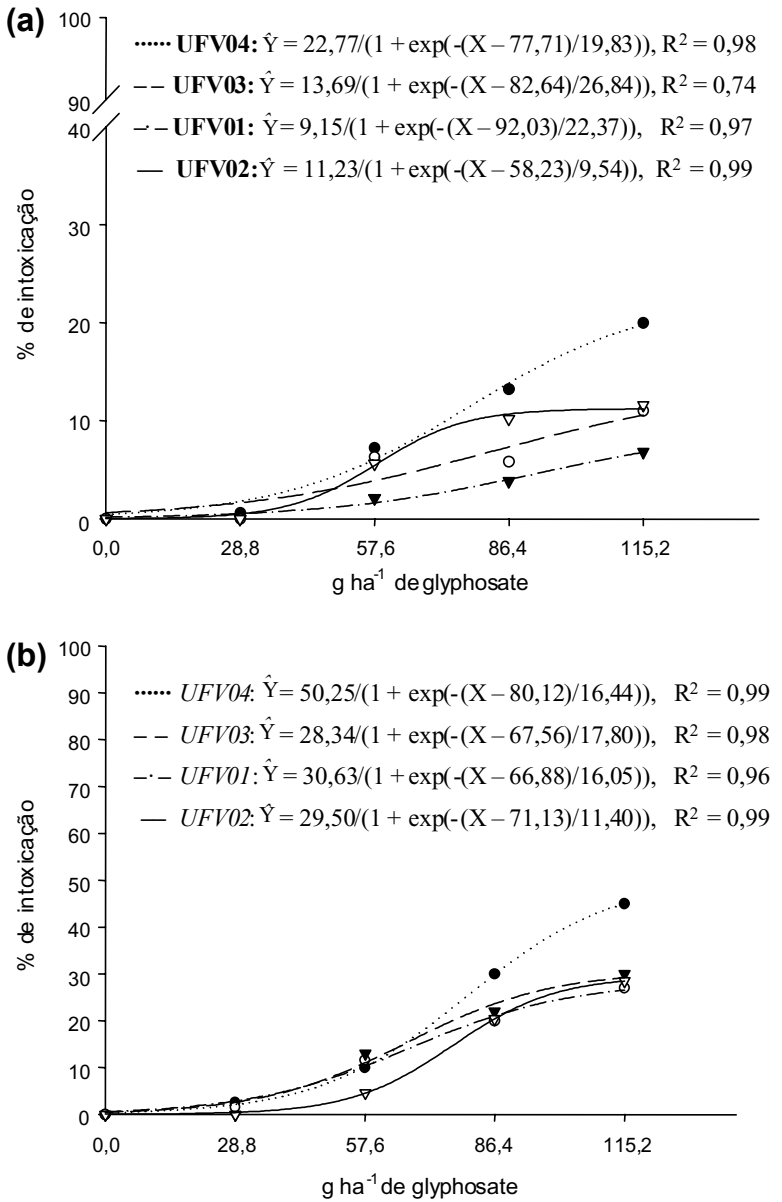

Figura 2 - Porcentagem de intoxicação de clones de eucalipto submetidos à deriva simulada com glyphosate em ensaio realizado no verão (a) e no outono/inverno (b), 21 dias após aplicação.
Entre os clones UFVO3e UFVO4, suscetiveis à ferrugem, houve diferença em área afetada $(\mathrm{p}<0,10)$, número de pústulas por área $(\mathrm{p}<0,10)$, número de urediniós poros por pústula $(\mathrm{p}<0,05)$ e número de urediniósporos por área foliar $(\mathrm{p}<0,05)$, o que não foi observado $(\mathrm{p}>0,10)$ para área média por pústula. Não houve dife rença significativa entre as subdoses de glyphosate e na interação clone $\mathrm{x}$ subdoses $(p>0,05)$ em todas as variáveis supracitadas.

Os clones suscetiveis mantiveram a predisposição à infecção por P. psidii, sendo atribuída notas S2 e S3 de severidade tanto para plantas expostas ao glyphosate quanto para a testemunha (Tabela 1). O clone UFVO3 foi o mais suscetivel à doença (Tabela 1), apresentando maior número de pústulas por área foliar, maior porcentagem de área foliar afetada (Figura 3) e maior número de urediniósporos por pústula e por área foliar (Figuras 4 e 5).

Nos dois ensaios, observou-se diminuição da severidade da doença nos dois clones suscetiveis com o aumento das subdoses de glyphosate (Figuras 4 e 5). Plantas expostas à deriva do glyphosate apresentaram menor área foliar afetada por ferrugem, menor número de urediniósporos/pústula e menor número de urediniósporos/área foliar, em comparação com as plantas testemunhas (Figuras 4 e 5).

Tabela 1 - Severidade da ferrugem (Puccinia psidii) avaliada por escala diagramática com quatro classes de severidade (S0, S1, S2 e S3), segundo Junghnas et al. (2003), em clones de híbridos de E. grandis submetidos à deriva de glyphosate

\begin{tabular}{|c|c|c|c|c|c|}
\hline \multirow{2}{*}{ Clone } & \multicolumn{5}{|c|}{$\mathrm{g} \mathrm{ha}^{-1}$ de glyphosate ${ }^{1 /}$} \\
\hline & 0 & 28,8 & 57,6 & 86,4 & 115,2 \\
\hline & \multicolumn{5}{|c|}{ Ensaio realizado no verão } \\
\hline UFV0 2 & S0 & S0 & S0 & S0 & S0 \\
\hline UFV01 & S0 & S0 & So & S0 & S0 \\
\hline UFVO 4 & S3 & S3 & S3 & S2 & S2 \\
\hline \multirow[t]{2}{*}{ UFV03 } & S3 & S3 & $\mathrm{S} 3$ & $\mathrm{~S} 3$ & S3 \\
\hline & \multicolumn{5}{|c|}{ Ensaio realizado no outono/inverno } \\
\hline UFV0 2 & S0 & S0 & S0 & S0 & S0 \\
\hline UFV01 & So & So & So & So & So \\
\hline UFV0 4 & S3 & S2 & S1 & S1 & so \\
\hline UFV03 & S3 & S3 & S3 & S3 & $\mathrm{S} 0 *$ \\
\hline
\end{tabular}

1 Subdoses correspondentes a 0 (testemunha), 2, 4, 6 e $8 \%$ da dose de $1.440 \mathrm{~g} \mathrm{ha}^{-1}$ de glyphosate, respectivamente. $* 100 \%$ das plantas apresentaram morte dos ponteiros. S0 e S1 são resistentes à ferrugem e S2 e S3, suscetíveis. 
O caráter biotrófico de Puccinia psidii, somado à característica desse patógeno de infectar e se desenvolver bem em tecidos jovens e sadios, pode ser uma possivel explicação para a menor severidade da doença em plantas expostas à deriva, haja vista os distúrbios fisiológicos, anatômicos e estruturais verificados em plantas intoxicadas por glyphosate. Este herbicida atua sobre a atividade enzimática da 5-enol-piruvil shiquimato-3-fosfato sintase (EPSPS), inibindo a sintese dos aminoácidos aromáticos triptofano, tirosina e fenilalanina (Kruze et al., 2000; Trezzi et al., 2001). Conseqüentemente, além de inibirem a fotossíntese, é possivel que plantas tratadas com glyphosate apresentem deficiência na sintese protéica e de vários outros compostos aromáticos importantes, como vitaminas ( $\mathrm{K}$ e E), hormônios (auxina e etileno), alcalóides, lignina, antocianina, entre outros. Deficiências e desequilíbrios nutricionais e mudanças morfoanatômicas e bioquímicas na planta podem predispor certos materiais genéticos a maior severidade de doenças. Os efeitos fisiológicos do glyphosate em eucalipto podem causar distúrbios bioquímicos e, conseqüentemente, o desbalanço entre os compostos orgânicos e inorgânicos da planta. Teores foliares de $\mathrm{Ca}, \mathrm{Mg}, \mathrm{Fe}, \mathrm{Mn}$ e $\mathrm{B}$ superiores, em comparação com a testemunha, foram observados em plantas que receberam doses de 345,6 e 691,2 $\mathrm{g} \mathrm{ha}^{-1}$ de glyphosate, em deriva simulada, não havendo relação entre os sintomas provocados pelo glyphosate e a deficiência de nutrientes (Siqueira et al., 2004).

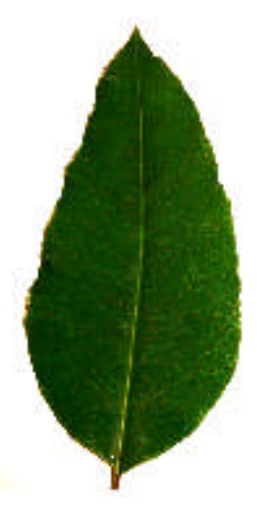

Clone UFV0 1

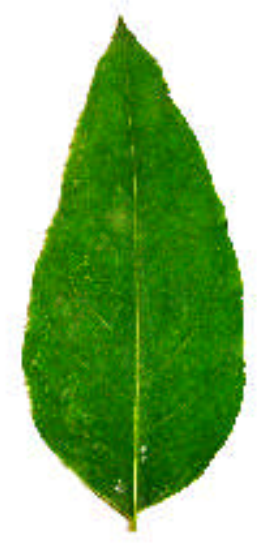

Clone UFV02

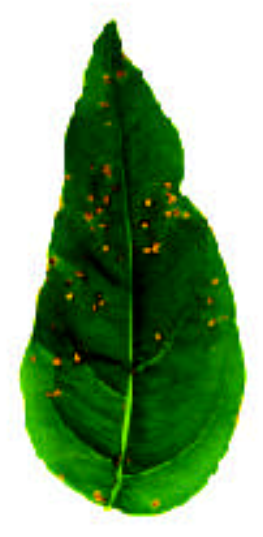

Clone UFV04
Puccinia psidii só infecta tecidos jovens e tenros da parte aérea da planta (Alfenas et al., 2004). Dentre os efeitos do glyphosate em eucalipto, ressaltam-se as necroses seguidas de senescência de folhas jovens. Adicionalmente, foi verificado um aspecto coráceo das folhas de plantas tratadas com doses superiores a $86,4 \mathrm{~g} \mathrm{ha}^{-1}$ de glyphosate, também relatado como sintoma de intoxicação em outros ensaios com deriva simulada de glyphosate em eucalipto (Tuffi Santos et al., 2005). O enrijecimento dos tecidos foliares e o possivel espessamento da cutícula epidérmica ocasionado pelo glyphosate podem reduzir a penetração do fungo, como observado em folhas velhas de plantas suscetiveis (Xavier et al., 2001).

Efeitos preventivos e curativos do glyphosate na incidência de ferrugem do trigo e de soja resistente ao herbicida foram relatados por Feng et al. (2005) em condições controladas e no campo. Nesse trabalho, folhas de trigo préinoculadas com Puccinia triticina e protegidas do contato com o glyphosate pulverizado no restante da planta apresentaram menor incidência de ferrugem que nas plantas testemunhas (sem glyphosate), ressaltando o efeito sistêmico do herbicida na diminuição da severidade dessa doença.

Anderson \& Kolmer (2005) observaram que, com a aplicação do glyphosate, houve redução ou inibição total da infecção por $P$. triticina e por $P$. graminis em genótipos de trigo resistentes a esse produto. Entretanto, os autores não encontraram efeito curativo do

Figura 3 - Espectro de infecção e severidade da ferrugem (Puccinia psidii) em folhas de eucalipto.

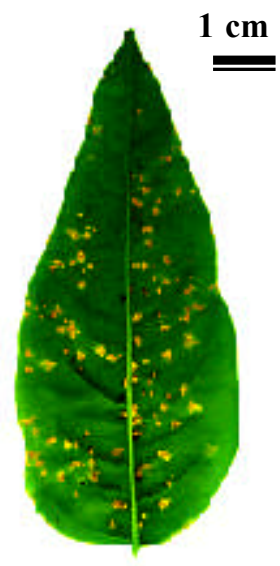

Clone UFV03

Planta Daninha, Viçosa-MG, v. 25, n. 1, p. 139-147, 2007 

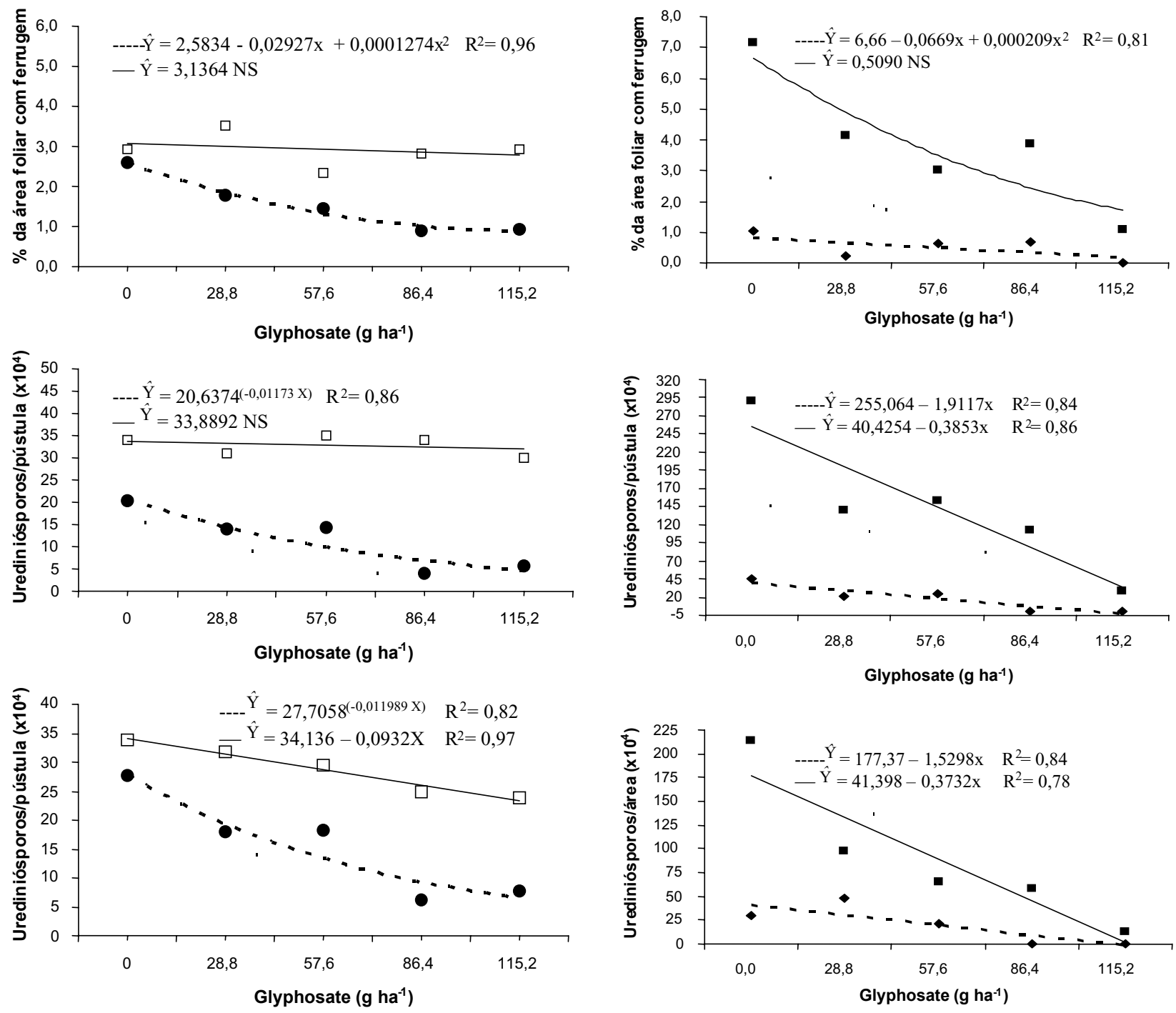

Figura 4 - Desenvolvimento de Puccinia psidii em plantas de eucalipto submetidas à deriva de glyphosate na época de verão. ----- clone UFV04; - clone UFV03.

herbicida na ferrugem do trigo, e sua aplicação não afetou o desenvolvimento de pústulas de Puccinia sp. preestabelecidas, sugerindo o efeito inibitório do herbicida nos estádios iniciais de infecção. A germinação de aeciósporos de Puccinia lagenophora, usado no biocontrole de Senecio vulgaris, é significativamente menor quando da adição de 0,1125 e 0,0565 mg e.a. $\mathrm{mL}^{-1}$ de glyphosate no meio de cultura, quando comparado à adição de água (Wyss \& Muller-Scharer, 2001).

Acredita-se também que o herbicida na superfície epidérmica da folha do eucalipto pode influenciar os processos de infecção e

Figura 5 - Desenvolvimento de Puccinia psidii em plantas de eucalipto submetidas à deriva de glyphosate na época de outono/inverno. ----- clone UFV04; - clone UFV03.

sobrevivência dos esporos de P. psidii. Berner et al. (1991) constataram que aplicações de glyphosate, em formulações com ou sem surfatante, inibiram o crescimento micelial de Calonectria crotalariae. An alogamente, a intoxicação de estirpes de Bradyrhizobium por glyphosate, in vitro, foi descrita por Santos et al. (2004), havendo diferença de toxidez entre as formulações do herbicida. A presença de diferentes substâncias químicas na formulação do herbicida, como solventes, surfatantes e agentes molhantes, pode modificar e, provavelmente, potencializar os efeitos negativos dos herbicidas em organismos (Kishinevsky et al., 1988; Malkones, 2000). 
O contato do glyphosate com plantas de eucalipto é freqüente, mesmo em situações nas quais alto nível tecnológico é empregado. No campo, a infecção natural de $P$. psidii em plantas de eucalipto pode acontecer antes, ao mesmo tempo ou após o contato das plantas com o herbicida. Assim, tornam-se necessários novos estudos com variações quanto à época de inoculação do fungo em relação ao contato do glyphosate com eucalipto para melhor entendimento da interação patógeno $\mathrm{x}$ eucalipto $\mathrm{x}$ glyphosate.

Conclui-se que o glyphosate, em deriva, não alterou o nivel de resistência do eucalipto à ferrugem em dois clones heterozigotos para resistência à ferrugem. Entre os genótipos suscetíveis, o clone UFVO3 mostrou maior intensidade da ferrugem que o UFVO4. Plantas dos clones suscetiveis à ferrugem, expostas à deriva de glyphosate, apresentaram menor área foliar afetada por pústulas, menor número de urediniósporos por pústula e menor número de urediniósporos por área foliar. Dos clones testados, o UFVO1 foi o mais tolerante e o UFVO4 o mais sensivel ao glyphosate.

\section{AGRADECIMENTOS}

À Suzano Papel e Celulose, pelo apoio financeiro e suporte na realização desta pesquisa.

\section{LITERATURA CITADA}

ALFENAS, A. C. et al. Clonagem e doenças do eucalipto. Viçosa, MG: Universidade Federal de Viçosa, 2004. 442 p.

ANDERSON, J. A.; KOLMER, J. A. Rust control in glyphosate tolerant wheat following application of the herbicide glyphosate. Plant Dis., v. 89, p. 1136-1142, 2005.

BERNER, D. K.; BERGGREN, G. T.; SNOW, J. P. Effects of glyphosate on Calonectia crotalariae and red crown rot of soybean. Plant Dis., v. 75, p. 809-813, 1991.

BUCHANAN, B. B.; GRUISSEM, W.; JONES, R. L. Biochemistry and molecular biology of plants. 3.ed. Rocjville: American Society of Plant Physiologists, 2000. $1367 \mathrm{p}$.

FENG, P. C. C. et al. Glyphosate inhibits rust diseases in glyphosate-resistant wheat and soybean. Proc. Natl. Acad. Sci., v. 102, p. 17290-17295, 2005.
FRANS, R. E. Measuring plant responses. In: WILKINSON, R. E. (Ed.). Research methods in weed science. Southern Weed Science Society, 1972. p. 28-41.

JUNGHANS, D. T. et al. Resistance to rust (Puccinia psidii Winter) in Eucalyptus: mode of inheritance and mapping of a major gene with RAPD markers. Theor. App. Genetics, v. 108, p. 175-180, 2003.

JUNGHANS, D. T.; ALFENAS, A. C.; MAFFIA, L. A. Escala de notas para quantificação da ferrugem em Eucalyptus. Fitopatol. Bras., v. 28, n. 2, p. 184-188, 2003.

KISHINEVSKY, B. et al. Effects of some commercial herbicides on rhizobia and their symbiosis with peanuts. Weed Res., v. 28, p. 291-296, 1988.

KRUZE, N. D.; TREZZI, M. M.; VIDAL, R. A. Herbicidas inibidores da EPSPS: revisão de literatura. R. Bras. Herb., v. 1, n. 2, p. 139-46, 2000.

LÉVESQUE, C. A.; RAHE, J. E. Herbicide interaction with fungal root pathogens, with special reference to glyphosate. Ann. Rev. Phytopathol., v. 30, p. 579-602, 1992.

MALKONES, H. P. Comparison of the effects of differently formulated herbicides on soil microbial activities - a review. J. Plant Dis. Protect., v. 8, p. 781-789, 2000.

MILLER, D. K. et al. Response of non glyphosate resistant cotton to reduced rates of glyphosate. Weed Sci., v. 52, p. 178-182, 2004.

RIZZARD, M. A. et al. Ação dos herbicidas sobre o mecanismo de defesa das plantas aos patógenos. Ci. Rural, v. 33, n. 5, p. 957-965, 2003.

RUIZ, R. A. R. et al. Influência de temperatura, do tempo de molhamento foliar, fotoperíodo e da intensidade de luz sobre a infecção de Puccinia psidii em eucalipto. Fitopatol. Bras., v. 14, p. $55-61,1989$.

SANTOS, J. B. et al. Effects of different glyphosate commercial formulations on Bradyrhizobium strains. Planta Daninha, v. 22, n. 2, p. 293-299, 2004.

SIQUEIRA, C. H. et al. Crescimento e concentração de nutrientes na parte aérea de eucalipto sob efeito da deriva de glyphosate. FERTIBIO 2004, Lajes. Resumos Expandidos... Lajes: 2004. CD-ROM.

SRIVASTAVA, L. M. Plant growth and development. Hormones and environment. San Diego, California: Elsevir Science, 2001. $771 \mathrm{p}$.

TUFFI SANTOS, L. D. et al. Crescimento e morfoanatomia foliar de eucalipto sob efeito de deriva do glyphosate. Planta Daninha, v. 23, n. 1, p. 133-142, 2005. 
TUFFI SANTOS, L. D. et al. Morphological responses of different eucalypt clones submitted to glyphosate drift.

Environ. Exp. Bot., v. 59, p. 11-20, 2007.

TUFFI SANTOS, L. D. et al. Intoxicação de espécies de eucalipto submetidas à deriva de glyphosate. Planta Daninha, v. 24, n. 2, p. 359-364, 2006 b.

TREZZI, M. M.; KRUZE, N. D.; VIDAL, R. A. Inibidores de EPSPS. In: VIDAL, R. A.; MEROTTO JR., A. (Eds.). Herbicidologia. Porto Alegre: 2001. p. 37-45.

VIEIRA, R. G. et al. Fitointoxicação por herbicidas em áreas de reflorestamento de teca. In: CONGRESSO BRASILEIRO DA CIÊNCIA DAS PLANTAS DANINHAS, 25., 2006.

Brasília, Resumos... Brasília: Sociedade Brasileira da Ciência das Plantas Daninhas, 2006. p. 450.
XAVIER, A. A. et al. Infection of resistant and susceptible Eucalyptus grandis genotypes by urediniosporos of Puccinia psidii. Aust. Plant Pathol., v. 30, p. 277-281, 2001.

WYSS, G. S.; MULLER-SCHARER, H. Effects of selected herbicides on the germination and infection process of Puccinia lagenophora, a biocontrol pathogen of Senecio vulgaris. Biol. Control., v. 20, p. 160-166, 2001.

YAMASHITA, O. M.; GUIMARÃES, S. C. Respostas de cultivares de algodoeiro a subdoses de glyphosate. Planta Daninha, v. 23, n.4, p. 627-633, 2005.

YAMASHITA, O. M. et al. Deriva de glyphosate em mudas de varjão (Parkia multijuga). In: CONGRESSO BRASILEIRO DA CIÊNCIA DAS PLANTAS DANINHAS, 25., 2006, Brasília. Resumos... Brasília: Sociedade Brasileira da Ciência das Plantas Daninhas, 2006. p. 449. 